\title{
MAINTENANCE OF INTERCHANGE HETEROZYGOSITY IN CULTIVATED RYE, SECALE CEREALE L.
}

\author{
M. CANDELA, A. M. FIGUEIRAS and J. R. LACADENA \\ Departmento de Genética, Facultad de Biología, Universidad Complutense, Madrid, Spain
}

Received 7.xi.78

\begin{abstract}
SUMMARY
The maintenance for several generations of interchange heterozygosity in both experimental and cultivated fields of rye is analysed. An experimental analysis of interchange heterozygotes has been carried out to ascertain whether only one or several translocations exist in the population. Interchange heterozygosity is discussed on the basis of the karyotypic orthoselection model. The maintenance of a constant frequency (20 per cent) of structural heterozygotes for several generations suggests the existence of an equilibrium. The possible mechanisms involved in such an equilibrium are discussed.
\end{abstract}

\section{INTRODUGTION}

IN 1975, Candela and Lacadena reported a natural population of cultivated rye, Secale cereale L., from the locality of Ailés (Zaragoza, Spain) showing structural heterozygosity for reciprocal translocations. Random samples taken in two successive generations (1973-74, 1974-75) showed 21 per cent of plants to be heterozygous for chromosomal interchanges. This chromosomal polymorphism could be due to one or several translocations; in the latter case the frequency of structural heterozygotes found would reflect heterozygosity for different interchanges. Additional data on the maintenance for several generations of this structural heterozygosity are reported in the present paper. Furthermore, an experimental analysis of interchange heterozygotes has been carried out to ascertain whether only one or several translocations exist in the population.

\section{MATERIAL AND Methods}

The rye population analysed (henceforth identified as " Ailés" cultivar) comes from the locality of Ailés (Zaragoza, Spain) where it has been cultivated for many years. No chemicals have been used on the population. Starting from an original sample taken from the field, experimental populations were grown outdoors in small plots for three successive generations (Al to A3, from 1973-74 to 1975-76). Each population was Iarge enough (about 2000 plants) to avoid genetic drift and inbreeding effects. Cytological observations were made on random samples from these experimental fields. In addition, samples ( $\mathrm{Cl}$ and $\mathrm{C} 2)$ from the field crop were also analysed (see fig. 1).

Classification of each plant as a structural homozygote or heterozygote was made at Metaphase I of meiosis. Homozygous individuals show seven bivalents while the heterozygotes show multivalent configurations. However, this simple observation does not permit, as a rule, either a distinction 


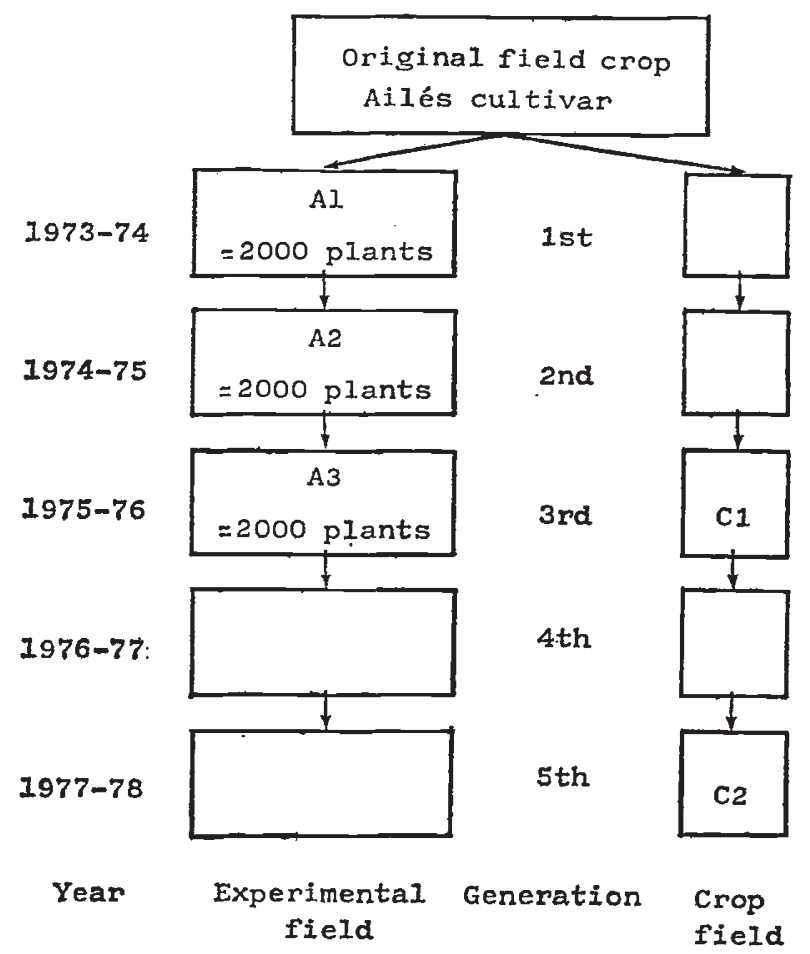

Frg. 1.-Experimental and natural populations of cultivated rye analysed.

between homozygotes for the standard (NN) and for translocated (TT) chromosome arrangements, or the determination whether different heterozygotes carry the same translocations.

The frequency of interchange homozygotes was estimated by analysing the offspring of crosses between 26 homozygous plants from the A3 population and plants from the "Elbon" cultivar which has a uniform standard arrangement (NN). If the A3 plant tested is homozygous for the standard arrangement (NN) the offspring will show seven bivalents at Metaphase I; if it is homozygous for one or more translocations $\left(T_{1} T_{i}\right)$ the offspring will show multivalent configurations.

To determine whether only one or more interchanges are present in the population, 11 single heterozygotes $\left(1^{\mathrm{IV}}+5^{\mathrm{II}}\right)$ from the A2 population were analysed by crossing one of them, taken as a tester, to the remainder. Additional crosses were also made. When two structural heterozygotes carry the same translocation their common offspring will show a $1: 1$ ratio of homozygotes (NN or TT) and single heterozygous (NT) plants. If both translocations are different, double heterozygotes will be expected in their offspring with a probability of $0 \cdot 25$. When two different translocations involve the same chromosome, the double heterozygote will show a configuration of $1^{\mathrm{VI}}+4 \mathrm{II}$ at Metaphase I (fig. 2), whereas if the two translocations do not involve any common chromosome the double heterozygote will show a configuration of $2^{\mathrm{IV}}+3^{\mathrm{II}}$ at Metaphase I (fig. 3). 
TABLE 1

Frequencies of structural homozygous and heterozygous individuals found in different populations of the "Ailés" cultivar of rye

\begin{tabular}{|c|c|c|c|c|c|}
\hline \multirow[b]{2}{*}{ Population } & \multirow{2}{*}{$\begin{array}{c}\text { Structural } \\
\text { homozygotes } \\
7 \mathrm{II}\end{array}$} & \multicolumn{3}{|c|}{ Structural heterozygotes } & \multirow[b]{2}{*}{ Total } \\
\hline & & $1^{\mathrm{IV}}+5^{\mathrm{II}}$ & $I^{\mathrm{VI}}+4^{\mathrm{II}}$ & $2^{\mathrm{IV}}+3^{\mathrm{II}}$ & \\
\hline Al & $\begin{array}{c}58 \\
(78 \cdot 38 \%)\end{array}$ & $\begin{array}{c}15 \\
(20 \cdot 27 \%)\end{array}$ & - & $\begin{array}{c}1 \\
(1.35 \%)\end{array}$ & 74 \\
\hline A2 & $\begin{array}{c}45 \\
(78.95 \%)\end{array}$ & $\begin{array}{c}12 \\
(21.05 \%)\end{array}$ & - & - & 57 \\
\hline A3 & $\begin{array}{c}98 \\
(80.33 \%)\end{array}$ & $\begin{array}{c}23 \\
(18.85 \%)\end{array}$ & $\begin{array}{c}1 \\
(0.82 \%)\end{array}$ & - & 122 \\
\hline $\mathrm{C} 1$ & $\begin{array}{c}59 \\
(78.66 \%)\end{array}$ & $\begin{array}{c}16 \\
(21.33 \%)\end{array}$ & - & - & 75 \\
\hline $\mathrm{C} 2$ & $\begin{array}{c}70 \\
(82.35 \%)\end{array}$ & $\begin{array}{c}15 \\
(17 \cdot 65 \%)\end{array}$ & - & - & 85 \\
\hline \multirow[t]{2}{*}{ Total } & \multirow{2}{*}{$\begin{array}{c}330 \\
(79.91 \%)\end{array}$} & 81 & 1 & 1 & \multirow[t]{2}{*}{413} \\
\hline & & & $20.09 \%$ & & \\
\hline
\end{tabular}

\section{RESULTS}

(i) Frequency of structural heterozygotes

The observed frequencies of structural homozygous and heterozygous individuals from the different populations and generations are shown in table 1. The data obtained indicate that the levels of structural heterozygosity are maintained at about 20 per cent in successive generations in both the experimental and the crop fields. A chi-square test of heterogeneity for homozygous versus heterozygous frequency (grouping single and double heterozygotes) is non-significant $\left(\chi^{2}=0.542\right.$, d.f. $\left.=4, \mathrm{P}>0.95\right)$.

The existence of double structural heterozygotes (see table 1) indicates that different reciprocal translocations exist in the populations (see below).

(ii) Estimation of the number of different chromosomes involved in the polymorphism

Metaphase I configurations of the offsprings obtained from crosses between single interchange heterozygotes are shown in table 2 . The plant A2-24 was arbitrarily taken as a tester and crossed to 10 other heterozygotes. Nine out of these 10 plants carried an interchange different from that of the plant A2-24 since double heterozygotes appeared in their offspring (fig. 6). Only the plant A2-12 seems to carry the same translocation as A2-24 since all the nine descendants observed showed $7 \mathrm{II}$ at Metaphase I. Because the occurrence of the critical configuration ( $2 \mathrm{TV}$ or $1^{\mathrm{VI}}$ ) has a probability of 0.25 , this conclusion has a probability of $\mathrm{P} \geqq 0.92$, a value obtained from the inequality $(1-0.25)^{9} \leqq 1-P$.

Although the plant A2-4l did not yield any double heterozygous progeny when crossed with A2-24, it differed from A2-12 and, consequently, from A2-24. This was expected since the translocation of plant A2-41 involves 
TABLE 2

Analysis of the offspring obtained from crosses between 11 single structural heterozygotes from the $A 2$ population of the " Ailes" " cultivar of rye

Metaphase I configurations of the offspring

\begin{tabular}{|c|c|c|c|c|c|}
\hline Cross & $7 \mathrm{II}$ & $1^{\mathrm{IV}}+5^{\mathrm{II}}$ & $\mathrm{IVI}^{\mathrm{VI}}+4^{\mathrm{II}}$ & $2^{\mathrm{IV}}+3^{\mathrm{II}}$ & Total \\
\hline A2 $2-12 \times$ A2-24 & 2 & 7 & - & - & 9 \\
\hline A2 $222 \times$ A2-24 & - & 1 & 1 & - & 2 \\
\hline A $2-24 \times$ A $2-36$ & - & - & 1 & - & 1 \\
\hline A2- $24 \times$ A2-41 & - & 7 & - & - & 7 \\
\hline A2-24 $\times$ A2-44 & 1 & 3 & 1 & - & 5 \\
\hline A2 $-24 \times$ A2 -45 & 2 & 4 & 1 & - & 7 \\
\hline A2-24 $\times$ A2-57 & - & 2 & - & 1 & 3 \\
\hline A2 $2-24 \times$ A2 -58 & - & 5 & 1 & - & 6 \\
\hline A2-24 $\times$ A2-61 & 1 & 3 & 1 & - & 5 \\
\hline A2-24 $\times$ A2-68 & 一 & 5 & - & 4 & 9 \\
\hline A2-12 $\times$ A2-41 & - & - & 1 & - & 1 \\
\hline A2-22 $\times$ A2-44 & - & - & 1 & - & 1 \\
\hline A2 $2-22 \times$ A2-61 & - & - & 1 & - & 1 \\
\hline A2 $-44 \times$ A2 $2-45$ & 3 & - & - & 1 & 4 \\
\hline A2-61 $\times$ A2-68 & 1 & - & 1 & - & 2 \\
\hline
\end{tabular}

the nucleolar organiser chromosome, while the interchange of plant A2-24 does not.

The interchanges carried by plants A2-24, A2-44, and A2-45 are all different since double heterozygotes have been found in the offspring of their mutual intercrosses. Since the plants A2-45 and A2-44 each have one different chromosome of the two involved in the A2-24 interchange, it is inferred that four different chromosomes are involved in these three translocations. None of the chromosomes is the one with the nucleolar organiser (fig. 4). This chromosome, however, is involved in other translocations (plants A2-41, A2-61, and A2-68 (fig. 5), and therefore at least five chromosomes of the rye complement are involved in the structural polymorphism. In addition, it can be inferred from fig. 6 that there are, at least, seven different interchanges, namely A2-24, A2-45, A2-44, A2-22, A2-61, A2-68, and A2-57. It is not possible to say whether translocations A2-36, A2-41, and A2-58 involve other additional interchanges.

\section{(iii) Frequency of the homozygotes}

From the crosses made between 26 structural homozygotes (NN or $\mathrm{T}_{\mathrm{i}} \mathrm{T}_{\mathrm{i}}$ ) with plants of the "Elbon" cultivar taken as a common tester, it was inferred that all of them are of the NN type.

\section{Discussion}

Intraspecific translocation polymorphisms have been reported both in cultivated (Müntzing and Prakken, 1941; Akdik and Müntzing, 1949) and in wild rye (Hrishi and Müntzing, 1960; Hrishi et al., 1969). The results given here show that the chromosomal polymorphism in the "Ailés" cultivar is due to several reciprocal translocations. Seven different interchanges have been detected among 11 heterozygotes analysed; it seems therefore reasonable to assume that there are many translocations in the population, each being present with low frequency. Since five chromosomes 


\section{Plate}
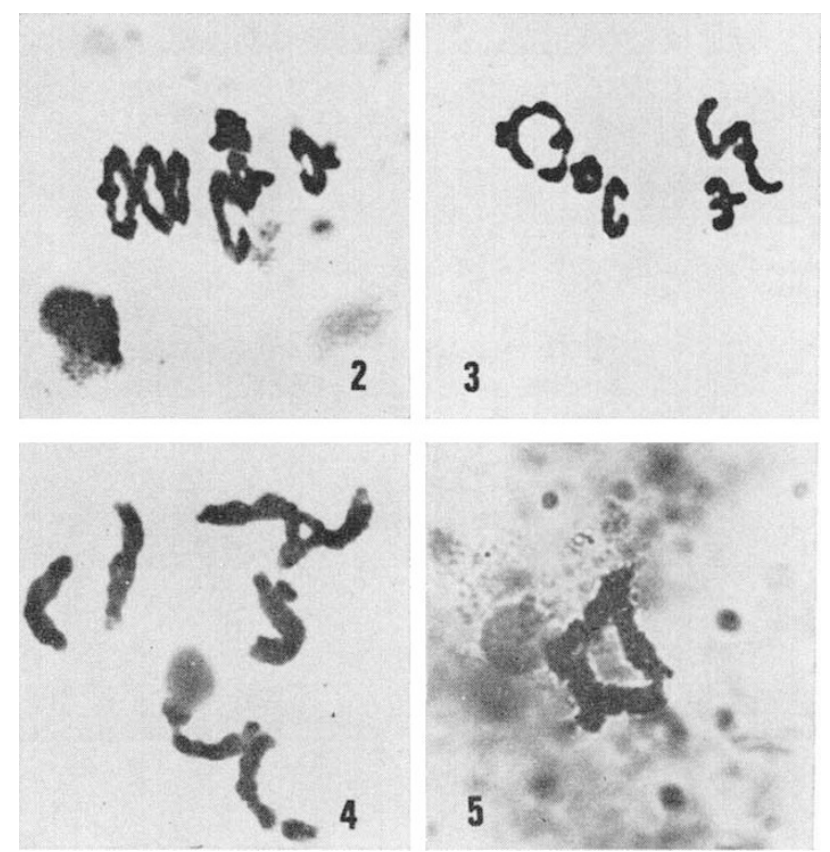

Figs. 2-5.-Meiotic configurations of rye interchange heterozygotes.

FIG. 2.-Metaphase I of a double heterozygote showing $\mathrm{I}^{\mathrm{VI}}+4^{\mathrm{II}}$.

FIG. 3.-Metaphase I of a double heterozygote showing $2^{\text {IV }}+3^{\text {II }}$.

FIG. 4.-Diplotene of a single heterozygote. None of the chromosomes involved in the interchange is the one with the nucleolar organiser.

FIG. 5.-Diplotene of a single heterozygote in which the nucleolar organiser chromosome is involved in the interchange. 


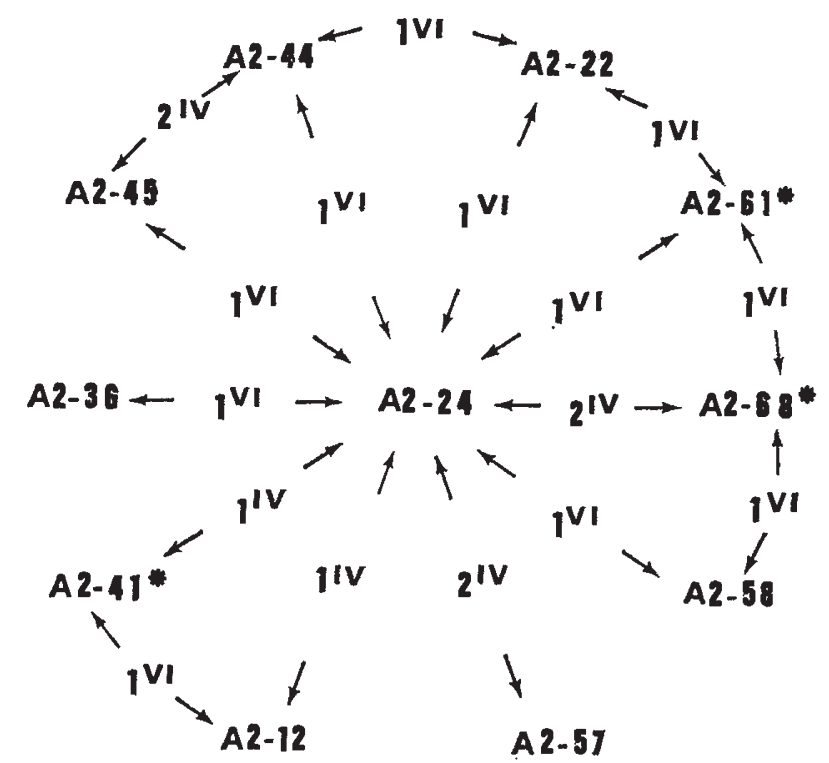

Fig. 6.-Critical configurations found in the offspring of crosses between single structural heterozygotes from the A2 population of the "Ailés" cultivar of rye. Asterisks stand for heterozygous plants in which the nucleolus organiser chromosome is involved in the interchange.

of the complement are involved in the seven different translocations, one may infer that probably all seven chromosomes of genome are involved in interchanges.

The results indicate that the frequency of homozygotes for a translocated arrangement is very low (none of the 26 homozygotes analysed was homozygous for a translocation). This agrees with the observations made by Bailey et al. (1978) who found that most of the rye interchange homozygotes for a particular translocation were inviable. However, in our case it is not necessary to attribute the lack of observed homozygotes to a general deleterious effect of structural homozygosis. Since many different interchanges are involved, the very low frequency of homozygotes could be simply due to the low frequency of each individual interchange $\left(q_{i}\right)$.

Let $p$ be the gametic frequency of the standard $(\mathrm{N})$ chromosomal arrangement and $q_{i}$ that of the translocated $T_{i}$ arrangement $\left(p+\Sigma q_{i}=1\right)$. The population will be formed by individuals $N N, N T_{1}, T_{i} T_{i}$, and $T_{i} T_{j}$. Individuals having other combinations of the above chromosome constitutions will not be considered here because their probability is practically zero.

If we assume that there are $n$ different interchanges $(i=n)$, all having the same frequency $\left(q_{\mathbf{i}}=q\right)$, then $p+n q=1$, and we can estimate $n \cdot q$ by the maximum likelihood method:

Chromosome constitution

Observed values

Expected relative frequencies

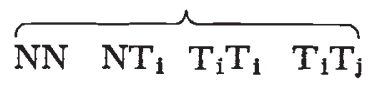

$\begin{array}{cccc}\mathrm{a}_{1} & \mathrm{a}_{2} & \mathrm{a}_{3} & \mathrm{a}_{4} \\ p^{2} & 2 n p q & n q^{2} & 2 n q^{2}\end{array}$


Then, $n \cdot q$ may be estimated as

$$
n \cdot q=\frac{\mathrm{a}_{2}+2 \mathrm{a}_{3}+2 \mathrm{a}_{4}}{2\left(\mathrm{a}_{1}+\mathrm{a}_{2}+\mathrm{a}_{3}+\mathrm{a}_{4}\right)}
$$

In the "Ailés" cultivar (see table 1 ), $a_{1}=330 ; a_{2}=81 ; a_{3}=0 ; a_{4}=2$. Therefore, $n \cdot q=85 / 826=0 \cdot 1$, and $p=\mathrm{I}-n q=0 \cdot 9$. Because $q=0 \cdot 1 / n$, the higher the number of different interchanges the lower their relative frequencies.

The presence of structural heterozygotes for many different translocations may indicate that the chromosome structure of the population is unstable and susceptible to chromosomal rearrangements. However, mechanisms have to exist in rye for avoiding the loss of fertility due to unbalanced gametes, given the high levels of interchange heterozygosity. In 26 plants from different generations of the "Ailés" cultivar the average alternate co-orientation (which gives rise to balanced gametes) is 75 per cent (Lacadena and Candela, 1977, and unpublished data). This agrees with the data reported by Bailey et al. (1978).

The maintenance of a constant frequency (20 per cent) of structural heterozygosity for several generations suggests the existence of an equilibrium. There is evidence supporting a superior fitness of interchange heterozygotes in rye (Rees, 1961; Bailey et al., 1976, 1978). However, since there are many different interchanges in the "Ailés" cultivar other explanations should be also considered. For instance, a mutation-selection equilibrium in which a possible selection against heterozygotes could be compensated by a continuous production of new rearrangements. In such a situation $u=s . q$, then one can expect that either mutation rate $(u)$ is high or selection pressure $(s)$ is low.

In the case of the selective neutrality of structural heterozygosis, the presence of interchanges in the population would simply be due to their accumulation over many generations. This would be in agreement with White's (1975, 1977) karyotypic orthoselection phenomenon. According to White, "particular types of rearrangement are especially likely to occur spontaneously in certain karyotypes rather than in others", and "similar rearrangements may have similar effects on the phenotype". Selective neutrality of structural heterozygotes would explain the fact that interchanges are found "floating" in high frequencies in allogamous plant populations (Stebbins, 1963).

Acknowledgments. - The authors thank Prof. Francisco J. Ayala for his helpful criticisms.

\section{RefERENGES}

AKdik, s., ANd muntzing, A. 1949. New cases of segmental interchanges and some other meiotic irregularities in rye. Hereditas, 35, 67-76.

BAILEY, R. J., REES, H., AND ADENA, M. A. 1978. Interchange heterozygosity and selection in rye. Heredity, 41, 1-12.

BAILEY, R. J., REES, H., AND JONES, L. M. 1976. Interchange heterozygotes versus homozygotes. Heredity, 37, 109-112.

CANDELA, N., AND LACADENA, J. R. 1975. Chromosomal polymorphism by reciprocal translocations in a natural population of cultivated rye, Secale cereale L.: A preliminary note. Anal. Inst. Bot. Cavanilles, 32, 649-657.

HRISHI, N., AND MÜNTZING, A. 1960. Structural heterozygosity in Secale kuprijanovi. Hereditas, $46,745-752$. 
HRISHI, N., MÜNTZING, A., AND RAMULU, F. s. 1969. Further data on structural heterozygosity in a strain of Secale kuprijanovi. Hereditas, 61, 339-347.

LACADENA, J. R., AND CANDEla, M. 1977. Centromere co-orientation at Metaphase I in interchange heterozygotes of rye, Secale cereale L. Chromosoma, 64, 175-189.

MüNTZING, A., AND PRAKKEN, R. 1941. Chromosomal aberrations in rye populations. Hereditas, 27, 273-308.

REES, H. 1961. The consequences of interchange. Evolution, 15, 145-152.

stebBrNs, G. L. 1963. Variation and Evolution in Plants. Columbia Univ. Press, New York. whrte, M. J. D. 1975. Chromosomal repatterning: Regularities and restrictions. (Proc. XII Inter. Cong. Genet., Berkeley, 1973), Genetics, 79, 63-72.

whrte, M. J. D. 1977. Modes of Speciation. W. H. Freeman and Co., San Francisco. 